\title{
Are there environments that help cultivate serendipity?
}

Minh-Hoang Nguyen

Ritsumeikan Asia Pacific University

Beppu, Oita 874-8577, Japan

January 17, 2022

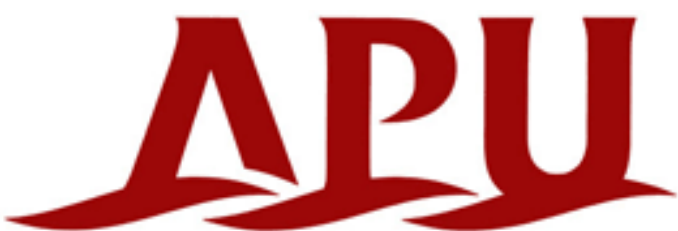

Ritsumeikan Asia Pacific University

$* * * * *$

I think yes. Even though the serendipity moment is unexpected, many scientists advocate that serendipity can be cultivated in some specific environments. Cultural, digital, and physical environments are vital in increasing the chance of encountering the necessary pieces of information that can lead to serendipity moments. Particularly, in a culture that endorses risk-taking, withholding of blame, and openness to new ideas and discussion, people are more likely to interact and share knowledge with each other, which in turn enhances the likelihood of facing unexpected valuable information or events (Cunha et al., 2010; Mendonça et al., 2008). Moreover, when a culture can tolerate a degree of autonomy for experiments, "controlled sloppiness", and minimal structure, it will also help stimulate serendipity (De Rond, 2014; Dew, 2009; Mendonça et al., 2008).

Apart from the cultural environment, digital and physical environments holding "triggerrich", "highlights triggers", "enables connections", and "enables capturing" factors are also able to facilitate serendipity processes (McCay-Peet \& Toms, 2015). In an experimental study of 47 digital users, Toms (2000) finds that suggestion tools can direct users to useful newspapers and increase serendipitous encounters. Zhang et al. (2012) suggest that the Auralist recommendation system can enhance serendipity among users listening to music while balancing it with other conflicting goals, like accuracy, diversity, and novelty. Additionally, the availability and design of physical spaces (e.g., sewing club, public library) for social connections, information sharing, cross contacts, diversity, pointers, imperfections, and explorability also affect serendipity (Björneborn, 2008; Pálsdóttir, 2011). 
Apparently, the environment plays a vital role in supporting one to encounter the "missing piece" as well as capitalize on it (Vuong et al., 2022). However, the environment is not the only factor that helps cultivate serendipity, but personal traits, skills, and mindset also do so (Delcourt, 2003; Dew, 2009; Diaz de Chumaceiro, 2004; Gaglio \& Katz, 2001; Napier \& Vuong, 2013; Vuong, 2016, 2018; Vuong, 2022; Vuong et al., 2022; Vuong \& Napier, 2015; Vuong \& Napier, 2014).

\section{References}

Björneborn, L. (2008). Serendipity dimensions and users' information behaviour in the physical library interface. Information Research, 13(4), 370.

Cunha, M. P. e., Clegg, S. R., \& Mendonça, S. (2010). On serendipity and organizing. European Management Journal, 28(5), 319-330.

De Rond, M. (2014). The structure of serendipity. Culture and Organization, 20(5), 342358.

Delcourt, M. A. (2003). Five ingredients for success: Two case studies of advocacy at the state level. Gifted Child Quarterly, 471), 26-37.

Dew, N. (2009). Serendipity in Entrepreneurship. Organization Studies, 30(7), 735-753.

Diaz de Chumaceiro, C. L. (2004). Serendipity and pseudoserendipity in career paths of successful women: Orchestra conductors. Creativity Research Journal, 16(2-3), 345-356.

Gaglio, C. M., \& Katz, J. A. (2001). The psychological basis of opportunity identification: Entrepreneurial alertness. Small Business Economics, 16(2), 95-111.

McCay-Peet, L., \& Toms, E. G. (2015). Investigating serendipity: How it unfolds and what may influence it. Journal of the Association for Information Science and Technology, 66(7), 1463-1476.

Mendonça, S., Cunha, M., \& Clegg, S. R. (2008). Unsought innovation: serendipity in organizations. Entrepreneurship and Innovation-Organizations, Institutions, Systems and Regions Conference, Copenhagen.

Napier, N., \& Vuong, Q. H. (2013). Serendipity as a Strategic Advantage? In T. Wilkinson (Ed.), Strategic Management in the 21st Century (pp. 175-199). Praeger/ABC-Clio.

Pálsdóttir, A. (2011). Opportunistic discovery of information by elderly Icelanders and their relatives. Information Research, 16(3), 485.

Toms, E. G. (2000). Understanding and facilitating the browsing of electronic text. International Journal of Human-Computer Studies, 52(3), 423-452.

Vuong, Q.-H. (2016). Global Mindset as the Integration of Emerging Socio-Cultural Values Through Mindsponge Processes: A Transition Economy Perspective. In J. Kuada (Ed.), Global Mindsets: Exploration and Perspectives (pp. 109-126). Routledge.

Vuong, Q.-H. (2018). The (ir)rational consideration of the cost of science in transition economies. Nature Human Behaviour, 2, 5.

Vuong, Q.-H., et al. (2022). Covid-19 vaccines production and societal immunization under the serendipity-mindsponge-3D knowledge management theory and conceptual framework. Humanities and Social Sciences Communications, 9, forthcoming. 
Vuong, Q.-H., Nguyen, M.-H., Khuc Q., Le T.-T. (2022). Environments and cultures that nurture serendipity strikes. In: QH Vuong. (Ed.) A New Theory of Serendipity: Nature, Emergence and Mechanism (pp. 157-174). Berlin, Germany: De Gruyter.

Vuong, Q.-H. (2022). A New Theory of Serendipity: Nature, Emergence and Mechanism. Berlin, Germany: De Gruyter.

Vuong, Q.-H., \& Napier, N. K. (2015). Acculturation and global mindsponge: an emerging market perspective. International Journal of Intercultural Relations, 49, 354-367.

Vuong, Q. H., \& Napier, N. K. (2014). Making creativity: the value of multiple filters in the innovation process. International Journal of Transitions and Innovation Systems, 3(4), 294-327.

Zhang, Y. C., et al.. (2012). Auralist: introducing serendipity into music recommendation. Proceedings of the fifth ACM international conference on Web search and data mining. 